\title{
Physiological changes at altitude in nonasthmatic and asthmatic subjects
}

\author{
Dianna Louie ${ }^{1,2}$, Peter D Paré MD FRCPC ${ }^{2}$
}

D Louie, PD Paré. Physiological changes at altitude in nonasthmatic and asthmatic subjects. Can Respir J 2004;11(3):197-199.

Exercised-induced asthma is not due to exercise itself per se, but rather is due to cooling and/or drying of the airway because of the increased ventilation that accompanies exercise. Travel to high altitudes is accompanied by increased ventilation of cool, often dry, air, irrespective of the level of exertion, and by itself, this could represent an 'exercise' challenge for asthmatic subjects. Exercise-induced bronchoconstriction was measured at sea level and at various altitudes during a two-week trek through the Himalayas in a group of nonasthmatic and asthmatic subjects. The results of this study showed that in mild asthmatics, there was a significant reduction in peak expiratory flow at very high altitudes. Contrary to the authors' hypothesis, there was not a significant additional decrease in peak expiratory flow after exercise in the asthmatic subjects at high altitude. However, there was a significant fall in arterial oxygen saturation postexercise in the asthmatic subjects, a change that was not seen in the nonasthmatic subjects. These data suggest that asthmatic subjects develop bronchoconstriction when they go to very high altitudes, possibly via the same mechanism that causes exercise-induced asthma.

\section{Key Words: Altitude; Asthma; Bronchoconstriction; Exercise}

E xercised-induced asthma is not a condition in itself, but rather a phenomenon that many people with asthma experience during bouts of strenuous exercise. Exercise-induced asthma is not due to exercise per se, but rather is due to by cooling and/or drying of the airway because of the increased ventilation that accompanies exercise (1). It has been shown that warming and humidifying the inspired air during exercise completely blocks the bronchoconstriction (2). Increased ventilation and the breathing of cold and/or dry air occur in individuals who go to high altitudes. In addition, exercise at high altitudes is accompanied by a greater increase in ventilation than at sea level, due to low ambient oxygen partial pressures. We hypothesized that asthmatics would be particularly susceptible to bronchoconstriction during sojourns at high altitudes because of the increased ventilation necessary for any given level of exercise combined with altered ambient air conditions. To test this hypothesis, we measured exercise-induced bronchoconstriction at sea level and at various altitudes during a two-week trek through the Himalayas in a group of nonasthmatic and asthmatic subjects.

\section{Des changements physiologiques en altitude chez des sujets non asthmatiques et asthma- tiques}

L'asthme à l'effort n'est pas causé par l'exercice même, mais par le refroidissement ou l'assèchement des voies respiratoires découlant de l'augmentation de la ventilation qui accompagne l'exercice. Les séjours en haute altitude s'accompagnent d'un accroissement de la ventilation d'air frais et souvent sec, quel que soit le taux d'effort. En soi, ce séjour pourrait représenter une épreuve " d'effort » pour les sujets asthmatiques. La bronchoconstriction d'effort a été mesurée au niveau de la mer et à diverses altitudes dans le cadre d'une randonnée de deux semaines d'un groupe de sujets non asthmatiques et asthmatiques dans les Himalaya. Les résultats de cette étude démontrent que chez les asthmatiques légers, le débit expiratoire de pointe à très haute altitude subissait une baisse marquée. Contrairement à l'hypothèse des auteurs, on ne remarquait pas de diminution supplémentaire importante du débit expiratoire de pointe après l'exercice chez les sujets asthmatiques à haute altitude. La saturation du sang artériel en oxygène chutait de manière significative après l'exercice chez les sujets asthmatiques, mais pas chez les sujets non asthmatiques. Ces données laissent supposer que les sujets asthmatiques développent une bronchoconstriction lorsqu'ils sont en très haute altitude, peut-être par le même mécanisme que celui qui provoque l'asthme à l'effort.

\section{PATIENTS AND METHODS}

The subjects in this study were 10 nonasthmatics and five asthmatics. The subjects were all residents of the lower mainland of British Columbia. The anthropometric and baseline physiological data for these individuals are shown in Table 1. The diagnosis of asthma was based on doctor's diagnosis. All of the asthmatics had relatively mild, controlled asthma; all had used an antiasthmatic medication at some time, but at the time of baseline measurements, only one was receiving regular therapy, consisting of inhaled salbutamol before exercise. During the trek, this individual also added $400 \mathrm{mg}$ of budesonide (Pulmicort, AstraZeneca, Canada) twice per day; the other asthmatics subjects used, as needed, inhaled bronchodilators without inhaled or oral corticosteroids. For one day at the highest altitude on the trek, all of the individuals, including the nonasthmatic subjects, received either dexamethasone $4 \mathrm{mg}$ or diamox $250 \mathrm{mg}$.

At sea level, before the trek and on the return, all of the subjects had measurements taken of peak expiratory flow (PEF) rate, blood pressure, heart rate and oxygen saturation. These

This study was the Grade 12 Science Fair Project of Ms Dianna Louie. Ms Louie conceived, designed and conducted the study. Dr Paré provided advice and assistance with data analysis

${ }^{1}$ Sir Winston Churchill Secondary School; ${ }^{2}$ University of British Columbia McDonald Research Laboratories/iCAPTURE Center, St Paul's Hospital, Vancouver, British Columbia

Correspondence and reprints: Ms Dianna Louie, clo Dr Peter D Paré, University of British Columbia McDonald Research Laboratories/ iCAPTURE Centre, St Paul's Hospital, 1081 Burrard Street, Vancouver, British Columbia V6Z 1Y6. Telephone 604-806-8346,

fax 604-806-8351, e-mail ppare@mrl.ubc.ca 
TABLE 1

Anthropometric and baseline physiological data for nonasthmatic and asthmatic subjects in a study examining physiological changes at altitude

\begin{tabular}{|c|c|c|}
\hline & $\begin{array}{l}\text { Nonasthmatic } \\
\text { subjects }\end{array}$ & $\begin{array}{l}\text { Asthmatic } \\
\text { subjects }\end{array}$ \\
\hline Number of subjects & 10 & 5 \\
\hline Male/female (n) & $5 / 5$ & $3 / 2$ \\
\hline Age (years) (mean \pm SD) & $25 \pm 14$ & $24 \pm 16$ \\
\hline Height $(\mathrm{cm})($ mean $\pm \mathrm{SD})$ & $170 \pm 10$ & $171 \pm 8$ \\
\hline Weight $(\mathrm{kg})($ mean $\pm \mathrm{SD})$ & $63.5 \pm 8.2$ & $61.7 \pm 5.4$ \\
\hline Peak expiratory flow (L/min) (mean \pm SD) & $502 \pm 45$ & $558 \pm 43$ \\
\hline Mean arterial pressure $(\mathrm{mmHg})($ mean $\pm \mathrm{SD})$ & $85 \pm 4$ & $88 \pm 5$ \\
\hline Heart rate (beats/min) (mean $\pm \mathrm{SD})$ & $76 \pm 11$ & $83 \pm 8$ \\
\hline Oxygen saturation $(\%)$ (mean \pm SD) & $97.1 \pm 1.3$ & $97.2 \pm 2.0$ \\
\hline
\end{tabular}

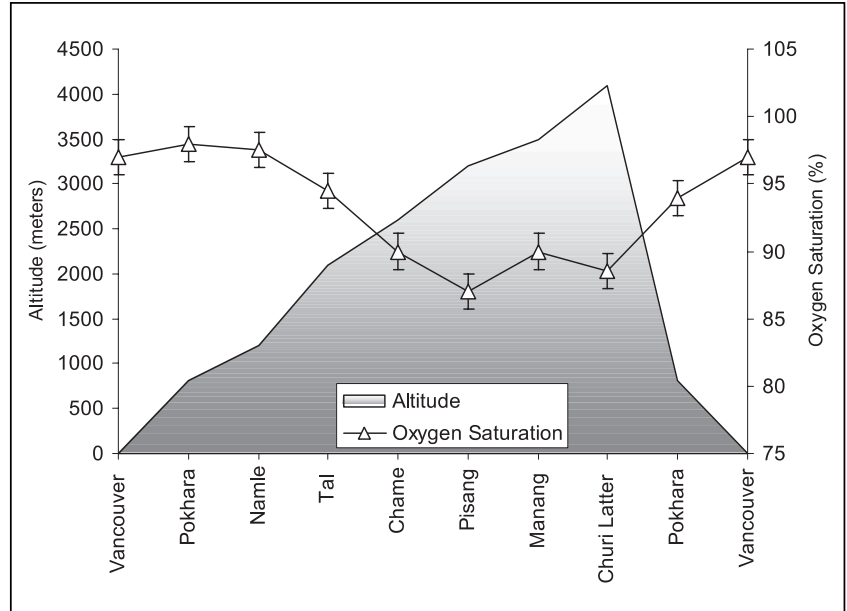

Figure 1) Altitude at different locations at which physiological measurements were taken, beginning in Vancouver, and reaching the highest elevations of $3500 \mathrm{~m}$ and $4100 \mathrm{~m}$ at Manang and Churi Latter, respectively. The vertical axis on the right shows the average pre-exercise oxygen saturation measurements (mean \pm SD) for all subjects, illustrating the expected decrease in resting oxygen saturation and the return to baseline values on return to Vancouver

measurements were taken before and immediately after a $200 \mathrm{~m}$ run. Measurements of PEF rate were always performed in the morning at approximately the same time of day. The oxygen saturation was measured using an oxygen saturation monitor (Nonin 8500M, Medical Inc, USA), PEF was measured using a peak flow meter (Breath-Alert, Carestream Medical, Australia and New Zealand), and blood pressure was measured using a blood pressure cuff (Tycos, Certified 6605315, USA) and stethoscope (Hewlett-Packard, USA).

\section{RESULTS}

Figure 1 shows the various locations at which measurements were taken as a function of altitude above sea level and the mean oxygen saturation for all individuals at these different sites. The mean $( \pm S D)$ resting heart rate at sea level in the asthmatic and nonasthmatic subjects was comparable $(83 \pm 4$ beats/min and $84 \pm 4$ beats/min, respectively); however, the peak postexercise heart rate was higher in the asthmatic than in the nonasthmatic subjects ( $128 \pm 6$ beats/min versus $110 \pm 5$ beats/min, respectively;

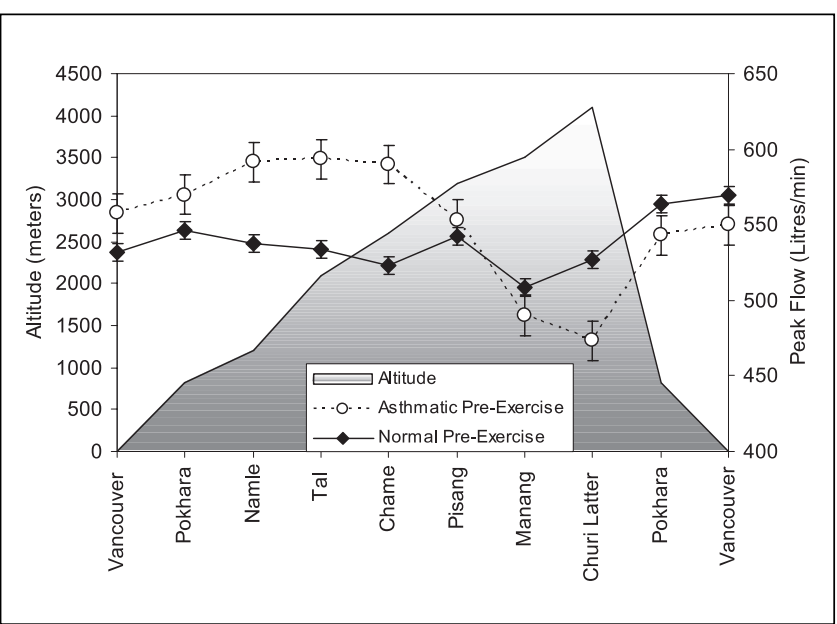

Figure 2) Mean values for peak expiratory flow (PEF) (L/min) at different locations and altitudes for nonasthmatic and asthmatic subjects. There was no change in mean PEF rates for the nonasthmatic subjects at any location. However, the PEF rates at Manang and Churi Latter were significantly reduced relative to values taken at sea level in the asthmatic subjects. The flow rates appear to decrease steeply between $2600 \mathrm{~m}$ and $3500 \mathrm{~m}$ in the asthmatic subjects

$\mathrm{P}<0.05)$. At the highest altitude, mean resting rates for the asthmatic and nonasthmatic subjects were $90 \pm 4$ beats/min and $85 \pm 6$ beats/min, and peak postexercise heart rates were $128 \pm 7$ beats/min and $133 \pm 9$ beats for these groups, respectively $(\mathrm{P}>0.05)$.

At sea level pre-exercise, the per cent predicted PEF rates for the nonasthmatic and asthmatic subjects were $101 \pm 9.3 \mathrm{~L} / \mathrm{min}$ and $107.8 \pm 21.5 \mathrm{~L} / \mathrm{min}$, respectively. Figure 2 shows the PEF values at the different locations and elevations pre-exercise in asthmatics and nonasthmatic subjects. At baseline, the asthmatic subjects had a slightly higher average PEF than nonasthmatic subjects; however, when this was expressed as per cent predicted, there was no significant difference between the groups. What is apparent is that there was a significant decrease in PEF with increasing altitude in the asthmatic but not in the nonasthmatic subjects. When PEF values at the two highest elevations were compared with the mean PEF values at sea level, there was a significant decrease in $\mathrm{PEF}$ in the asthmatic subjects $(-76 \pm 67 \mathrm{~L} / \mathrm{min}, \mathrm{P}<0.05)$ but a nonsignificant decrease in the nonasthmatic subjects $(-14 \pm 23 \mathrm{~L} / \mathrm{min}, \mathrm{P}>0.05)$ At sea level, the exercise challenge was associated with a small and insignificant change in PEF $(\triangle \mathrm{PEF})$ in both groups of subjects (Asthmatics $\triangle \mathrm{PEF}=-22 \pm 31 \mathrm{~L} / \mathrm{min}, \mathrm{P}=0.2$; nonasthmatics $\triangle \mathrm{PEF}=-3 \pm 29 \mathrm{~L} / \mathrm{min}$, $\mathrm{P}=0.6$ ). Figure 3 shows the changes in PEF from pre- to postexercise in the nonasthmatic and asthmatic subjects at the highest altitude reached. For this analysis, values for pre- and postexercise PEF at $3500 \mathrm{~m}$ and $4100 \mathrm{~m}$ were combined. There was no significant additional decrease in PEF flow after exercise in either the nonasthmatic or asthmatic subjects.

Figure 4 shows mean values for oxygen saturation pre- and postexercise in the nonasthmatic and asthmatic subjects at the two highest altitudes reached. There was a small but not significant decrease in oxygen saturation in the nonasthmatic subjects, but there was a significant further decrease in oxygen saturation in the asthmatics postexercise $(\mathrm{P}<0.04)$. 


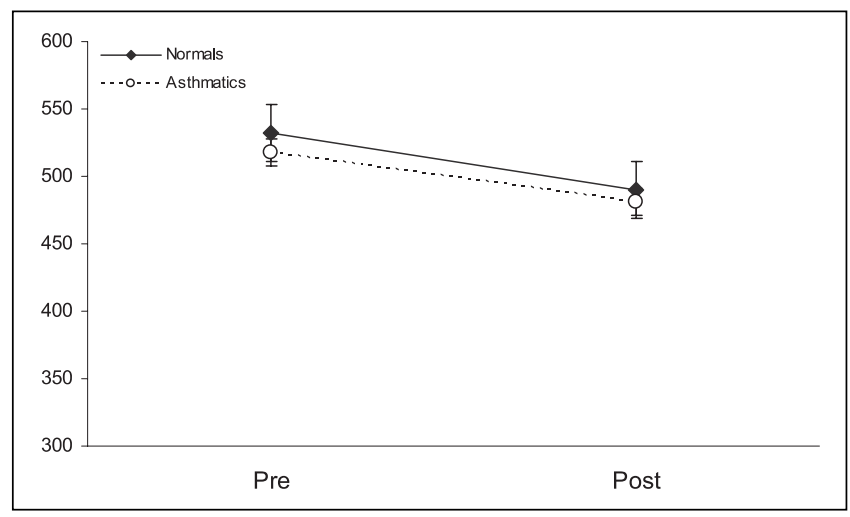

Figure 3) Mean peak expiratory flow (PEF) rates pre- and postexercise for asthmatic and nonasthmatic subjects, combining data at $3500 \mathrm{~m}$ and $4100 \mathrm{~m}$. There was no significant change in PEF for either group. Normals refers to nonasthmatic subjects

\section{DISCUSSION}

The results of this study shows that in mild asthmatic subjects, there was a significant reduction in PEF at high altitudes in the Himalayas. Contrary to our hypothesis, there was not a significant additional decrease in PEF after exercise in the asthmatic subjects at altitude. However, there was a significant fall in arterial oxygen saturation postexercise in the asthmatic subjects, a change that was not seen in the nonasthmatic subjects. These data suggest that mild asthmatic subjects develop bronchoconstriction at very high altitudes. Bronchoconstriction pre-exercise in these subjects may be related to the same mechanism that causes exercise-induced asthma. High altitude exposure is associated with excessive ventilation because of hypoxic conditions; in addition, the air temperature at the two highest locations was substantially lower than body temperature (Manang $8^{\circ} \mathrm{C}$, Churi Latter $0^{\circ} \mathrm{C}$ ), and the water content of air at these temperatures is substantially lower than the $47 \mathrm{mg} / \mathrm{L}$ that is present in fully saturated air at body temperature (3). Thus, simply going to a high altitude constitutes an 'exercise' challenge to asthmatic subjects. Interestingly, the asthmatics did not develop further bronchoconstriction during exercise at high altitudes, perhaps because their ventilation increased litthe beyond the marked hyperpnea already present. Although the subjects all attempted to run the prescribed $200 \mathrm{~m}$ at high altitude, they did so very slowly. Also, though measurements of ventilation during exercise were not obtained, it is possible that the increase in ventilation due to being at high altitude was as great or greater than that caused by exercise.

Despite this, the asthmatic subjects developed a significant fall in arterial oxygen saturation postexercise, a change that was not seen in the nonasthmatic subjects. There is evidence that arterial oxygen saturation is extremely dependent on the maintenance of alveolar ventilation at high altitudes (4). This is because diffusion becomes critically important for arterial oxygen saturation at altitude, and it is likely that a true alveolar capillary gradient for oxygen occurs when there are these

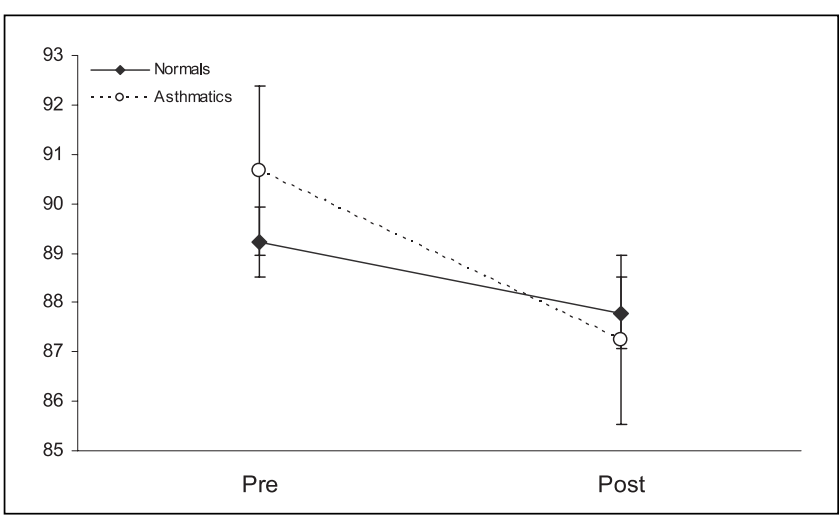

Figure 4) The pre-and postexercise mean arterial oxygen saturations for nonasthmatic and asthmatic subjects. Again, the values represent the combined baseline and postexercise values for both groups at $3500 \mathrm{~m}$ and $4100 \mathrm{~m}$. There is a small decrease in oxygen saturation in the nonasthmatic subjects, which did not achieve statistical significance. However, there was a significant fall in mean oxygen saturation in the asthmatic subjects postexercise. Normals refers to nonasthmatics

extremely low values of alveolar oxygen. The fall in oxygen saturation among the asthmatic subjects appears to be out of proportion to the decrease in expiratory flow. It may be that at low inspired oxygen pressures, small increases in ventilationperfusion rates mismatch have more effect on gas exchange at altitude than they would at sea level.

These data suggest that people with asthma are more prone to develop high altitude hypoxemia, predominantly related to bronchoconstriction occurring because of increased ventilation and cold, dry air conditions at altitude. The subjects in this study all had mild, well-controlled cases of asthma, and the results may not be generalizable for a broad range of asthmatic subjects. The asthmatic subjects were not specifically treated for exerciseinduced bronchoconstriction, and it is possible that regular therapy with inhaled corticosteroids and/or regular beta-adrenergic agonists may have attenuated or blocked this high altitude bronchoconstriction. However, the study was not designed to test this hypothesis. Although when properly controlled, people with asthma can lead a normal lifestyle, including going to high altitudes, these results suggest that they may develop mild bronchoconstriction and hypoxemia at high altitudes.

ACKNOWLEDGEMENTS: Ms Louie acknowledges the support of Mr Brian Sheffield, Dr Geoff Gabbott, Steve Brewster, Mr Ken Louie and Dr Heather Louie. Ms Louie's expedition to Nepal was sponsored in part by AstraZeneca, GlaxoSmithKline, Nesbitt Burns, Mead Johnson and the British Columbia Lung Association.

\section{REFERENCES}

1. Anderson SD, Daviskas E. The mechanism of exercise-induced asthma is ... J Allergy Clin Immunol 2000;106:453-9.

2. Deal EC Jr, McFadden ER Jr, Ingram RH Jr, Strauss RH, Jaeger JJ. Role of respiratory heat exchange in production of exercise-induced asthma. J Appl Physiol 1979;46:467-75.

3. Argyros GJ, Phillips YY, Rayburn DB, Rosenthal RR, Jaeger JJ. Water loss without heat flux in exercise-induced bronchospasm. Am Rev Respir Dis 1993;147:1419-24.

4. Schoene RB. Limits of human lung function at high altitude. J Exp Biol 2001;204:3121-7. 


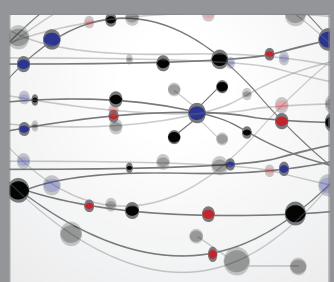

The Scientific World Journal
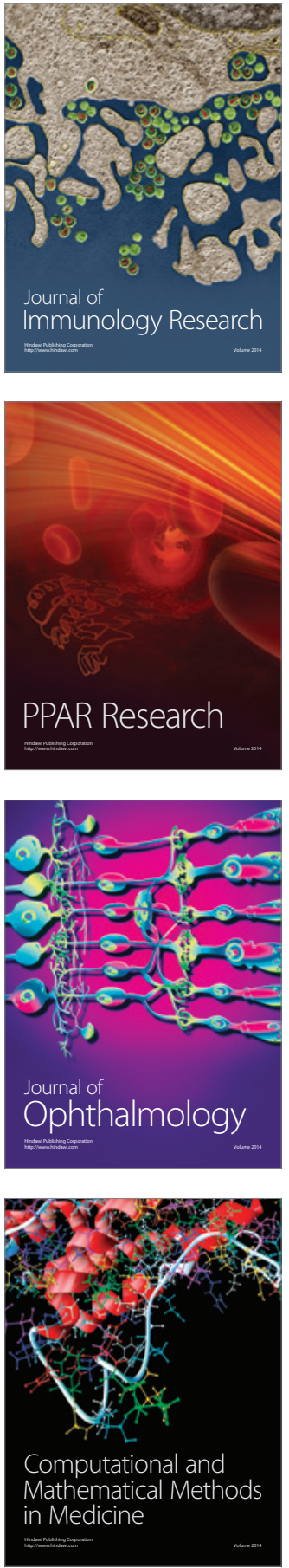

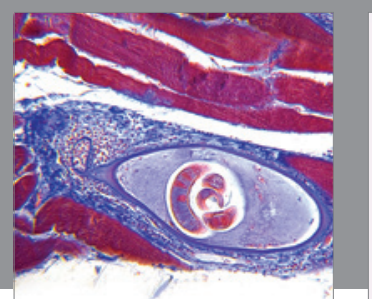

Gastroenterology Research and Practice

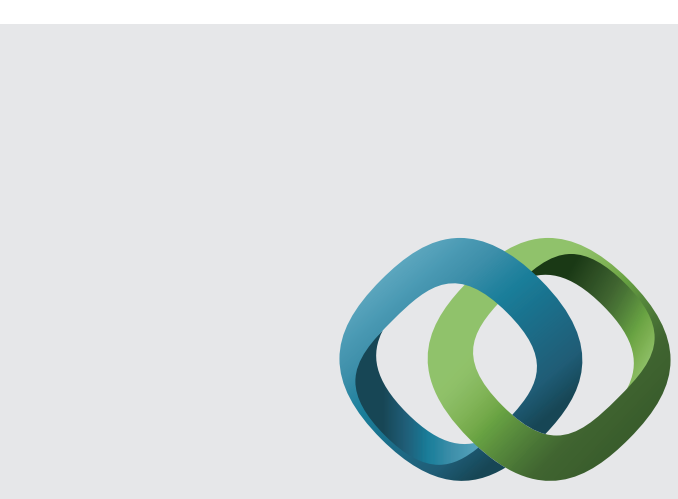

\section{Hindawi}

Submit your manuscripts at

http://www.hindawi.com
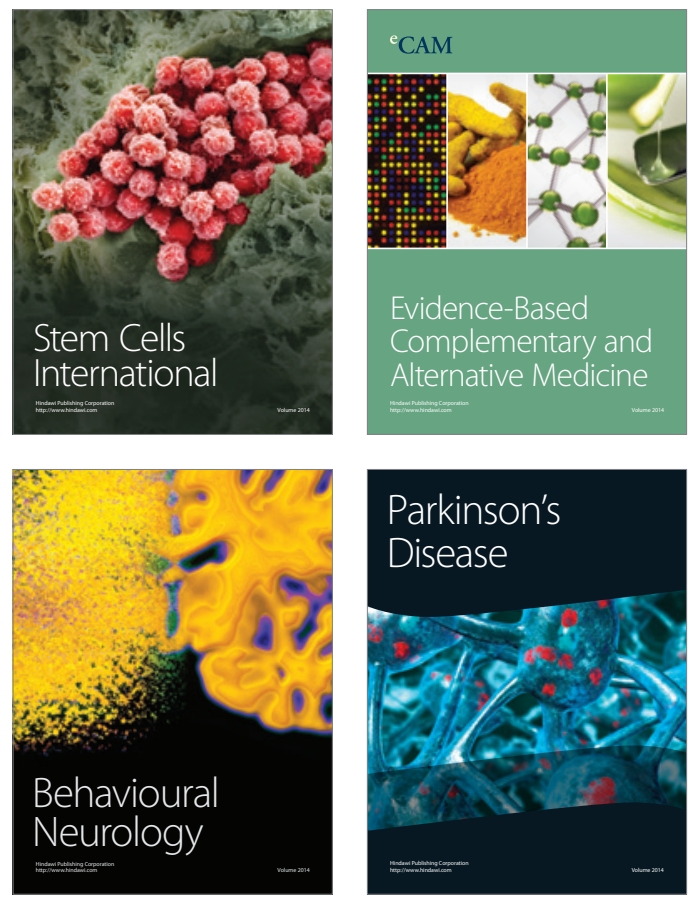
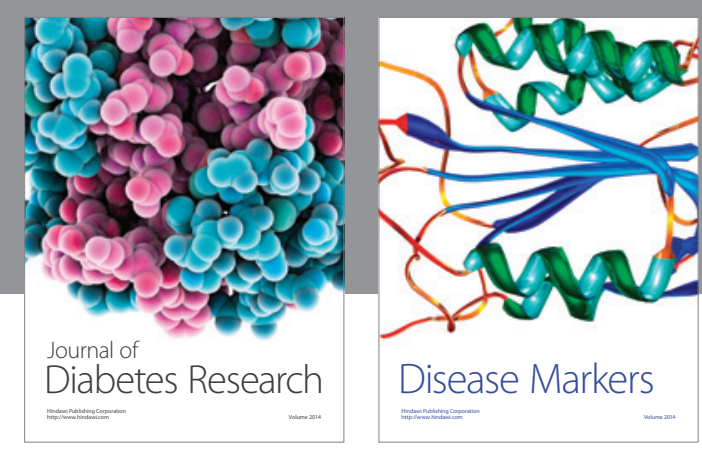

Disease Markers
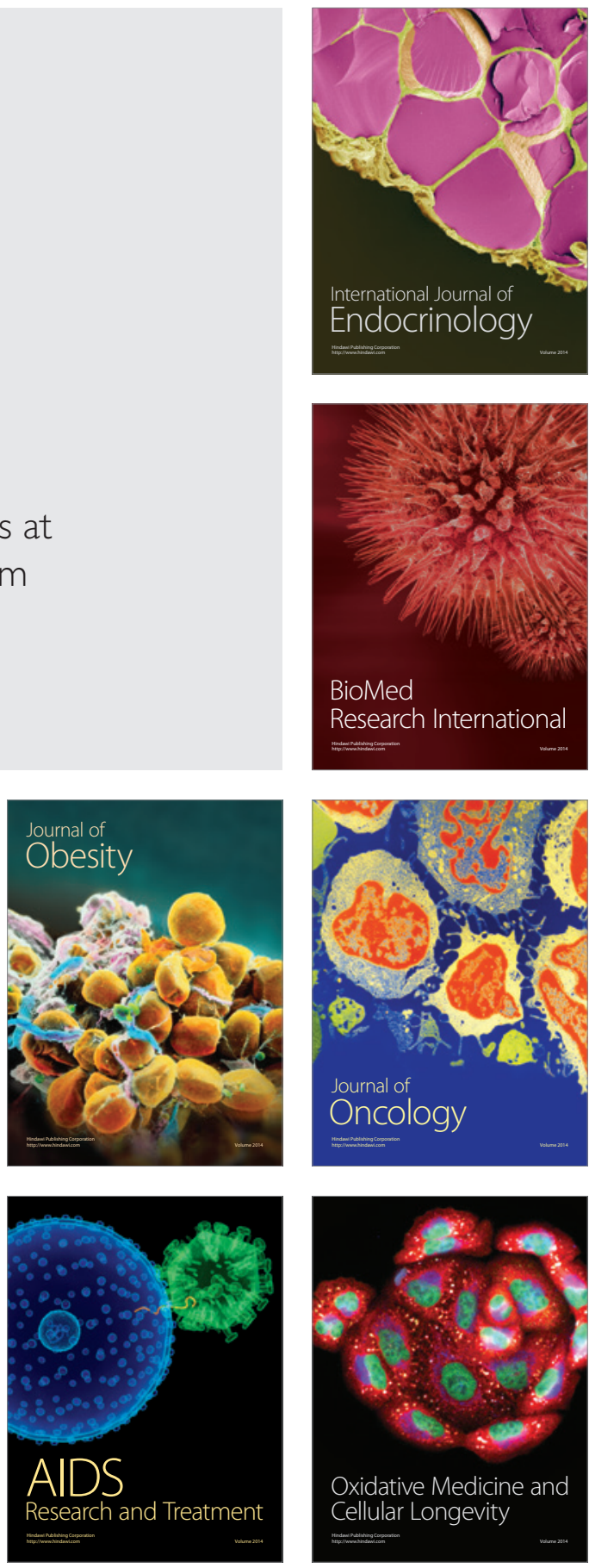